\title{
Unsuspected diversity of Niphargus amphipods in the chemoautotrophic cave ecosystem of Frasassi, central Italy
}

\author{
Jean-François Flot ${ }^{1}$, Gert Wörheide ${ }^{2}$, Sharmishtha Dattagupta ${ }^{1 *}$
}

\begin{abstract}
Background: The sulfide-rich Frasassi caves in central Italy contain a rare example of a freshwater ecosystem supported entirely by chemoautotrophy. Niphargus ictus, the sole amphipod species previously reported from this locality, was recently shown to host the first known case of a freshwater chemoautotrophic symbiosis. Since the habitat of $\mathrm{N}$. ictus is highly fragmented and is comprised of streams and lakes with various sulfide concentrations, we conducted a detailed study to examine the potential genetic diversity of this species within Frasassi.

Results: By sequencing one nuclear (ITS) and two mitochondrial (COI and 12S) regions, we show that four partially sympatric Niphargus clades are present in Frasassi. Morphological and behavioral data obtained for three of these clades are perfectly congruent with this molecular delineation and make it possible to distinguish them in the field. Phylogenetic analyses of $28 \mathrm{~S}$ ribosomal DNA sequences reveal that, among the four clades, only two are closely related to each other. Moreover, these four clades occupy distinct niches that seem to be related to the chemical properties and flow regimes of the various water bodies within Frasassi.

Conclusions: Our results suggest that four distinct Niphargus species are present in Frasassi and that they originated from three or four independent invasions of the cave system. At least two among the four species harbor Thiothrix epibionts, which paves the way for further studies of the specificity and evolutionary history of this symbiosis.
\end{abstract}

\section{Background}

Groundwater ecosystems are under constant threat from anthropogenic activities, yet remain relatively understudied to date [1]. Amphipods are a major component of the fauna inhabiting these ecosystems [2] and the largest genus among them is Niphargus, which is distributed across most of Europe [3]. Like many other groups of subterranean metazoans, Niphargus amphipods are almost always blind [4] and usually white [5], hence their generic name (from the Greek word niphargês meaning "white like snow"). The taxonomy of the genus Niphargus has been debated for the last 160 years [6] and is presently in a state of flux with the discovery of numerous cryptic taxonomic units [7-9]. Thus, understanding the biodiversity of this genus is of crucial

\footnotetext{
* Correspondence: sdattag@uni-goettingen.de

'Courant Research Centre "Geobiology", University of Göttingen, 37077 Göttingen, Germany

Full list of author information is available at the end of the article
}

importance to better grasp the origin and dispersion of the European groundwater fauna and to guide conservation efforts, as has previously been highlighted for gammarid amphipods in other ecosystems [10,11].

Unlike subterranean ecosystems that are fed by aboveground photosynthetic productivity [12], chemoautotrophic caves such as Movile in Romania [13], Frasassi in Italy [14] and Ayyalon in Israel [15] receive their energy input mostly in the form of the chemical hydrogen sulfide arising from underground reservoirs. Chemoautotrophic microorganisms use the energy derived from sulfide oxidation to fix carbon and thereby form the basis of the food chain in these thriving cave ecosystems. However, sulfide is toxic for aerobic organisms $[16,17]$ as it inhibits mitochondrial electron transport [18]; besides, it reacts with oxygen, causing hypoxia [19]. Hence, animals inhabiting sulfide-rich environments (such as marine sediments [20], hydrothermal vents [21], anchihaline caves [22] and sulfidic caves [23]) face
C Biomed Central

C 2010 Flot et al; licensee BioMed Central Ltd. This is an Open Access article distributed under the terms of the Creative Commons Attribution License (http://creativecommons.org/licenses/by/2.0), which permits unrestricted use, distribution, and reproduction in any medium, provided the original work is properly cited. 
specific metabolic challenges that they counter with avoidance behaviors, adaptations such as sulfide-oxidizing mitochondria and sulfide-binding proteins, or symbioses with sulfide-oxidizing bacteria [24].

Amphipods generally have a low tolerance to sulfide, even though some species may be quite resistant to hypoxia [25-28]. Niphargus ictus is the numerically dominant macroorganism in the sulfide-rich Frasassi cave ecosystem and has been the sole amphipod species reported to date from this location [14,29,30]. It thrives in the sulfidic streams and pools found in various parts of the cave, and a possible explanation for its tolerance to sulfide may lie in its symbiosis with chemoautotrophic sulfur-oxidizing bacteria of the genus Thiothrix [31]. Such chemoautotrophic symbioses are common in marine environments [32], but appear much rarer in freshwater where the $N$. ictus symbiosis is the only example reported to date.

Caves in Frasassi are developed in a limestone platform interspersed with a network of fractures that influence its hydrogeology [14] and could cause habitat fragmentation. Furthermore, the streams and lakes within the cave system have widely different sulfide and oxygen concentrations [33], which could lead to the occurrence of distinct Niphargus populations with varying tolerances to sulfide and hypoxia. To test these hypotheses, we sequenced mitochondrial and nuclear sequence markers for 184 Niphargus samples collected throughout the accessible parts of the cave system and complemented these molecular analyses with morphological and behavioral observations. Since our study unexpectedly revealed the presence of four Niphargus clades within Frasassi, we further examined the relationship between these clades by building a $28 \mathrm{~S}$ ribosomal DNA (rDNA) phylogeny including all Niphargus sequences presently available in GenBank.

\section{Results}

\section{Molecular analyses}

For each marker analyzed (12S, ITS, COI), results obtained using distance, parsimony and likelihood methods were congruent in delimiting four Niphargus clades among our samples (Figures 1, 2 and 3). Clade 1 comprised 75 individuals collected in five sampling sites in the north-eastern part of the cave complex (Figure 4), Clade 2 grouped 94 samples from all sites except three (where only Clade 1 was present), Clade 3 comprised 13 specimens from a single location on the northern side of the river (Il Bugianardo), and Clade 4 was represented by only two individuals from one remote site in the south (Lago Primo). Bootstrap values for the monophyly of the clades were very high (>99) using all three phylogenetic methods. Some locations were sampled more than one time in two or three different years (Table 1) but no time variation in the geographical repartition of the clades was detected. Average patristic distances between clades calculated from the COI tree (Table 2) were all above the 0.16 threshold proposed for species delimitation in Crustacea [34]; the lowest value was found for the distance between Clades 3 and 4, indicating that these two clades are the most closely related among the four.

A $28 \mathrm{~S}$ rDNA phylogeny of the genus Niphargus, including representative sequences from each Frasassi clade and all sequences available in GenBank, confirmed the separation between the clades and the close relationship between Clades 3 and 4 (Figure 5). The Niphargus present in Frasassi do not form a monophyletic group within the genus but fall instead into three distinct regions of the tree.

\section{Morphological analyses}

The morphometric analysis of seven quantitative characters shows that Clades 1-3 are morphologically distinct, with no overlap among them (Figure 6). The first component (horizontal on the figure) explained $87.9 \%$ of the variation (eigenvalue: 0.164 ) and distinguished Clade 3 from the other two predominantly based on its larger gnathopods. The second component (vertical) explained $8.4 \%$ of the variation (eigenvalue: 0.016 ) and distinguished Clade 2 from the other two based on its smaller head, longer antennae and deeper ventral channel (located between the coxal plates and bases of pereopods V to VII [35]).

Only the morphology of Clade 2 individuals corresponds to the published description of N. ictus [30]: Clade 1 individuals seem related to $N$. longicaudatus, a complex of several cryptic species or subspecies in need of taxonomic revision [9], whereas Clade 3 shares some morphological characteristics with the $N$. rejici species complex found in Slovenia and some Adriatic islands [36]. As for Clade 4, for which only two badly damaged samples are available at the present time, its morphology appears similar to Clade 3 (also its closest relative in Frasassi according to our molecular data) but more specimens need to be collected before definite conclusions can be reached regarding its identity.

\section{Behavioral observations}

The behavior of Clade 1 individuals was observed in two sites (Grotta Sulfurea and Sorgente del Tunnel), where they were found to spend most of their time crawling on their sides on bacterial mats and sediment. When disturbed, they swam poorly and for short durations (less than five seconds). In contrast, Clade 2 individuals observed in Lago Verde were found to be strong swimmers, achieving speeds of 1-2 body lengths per second, and were able to swim continuously for more than 


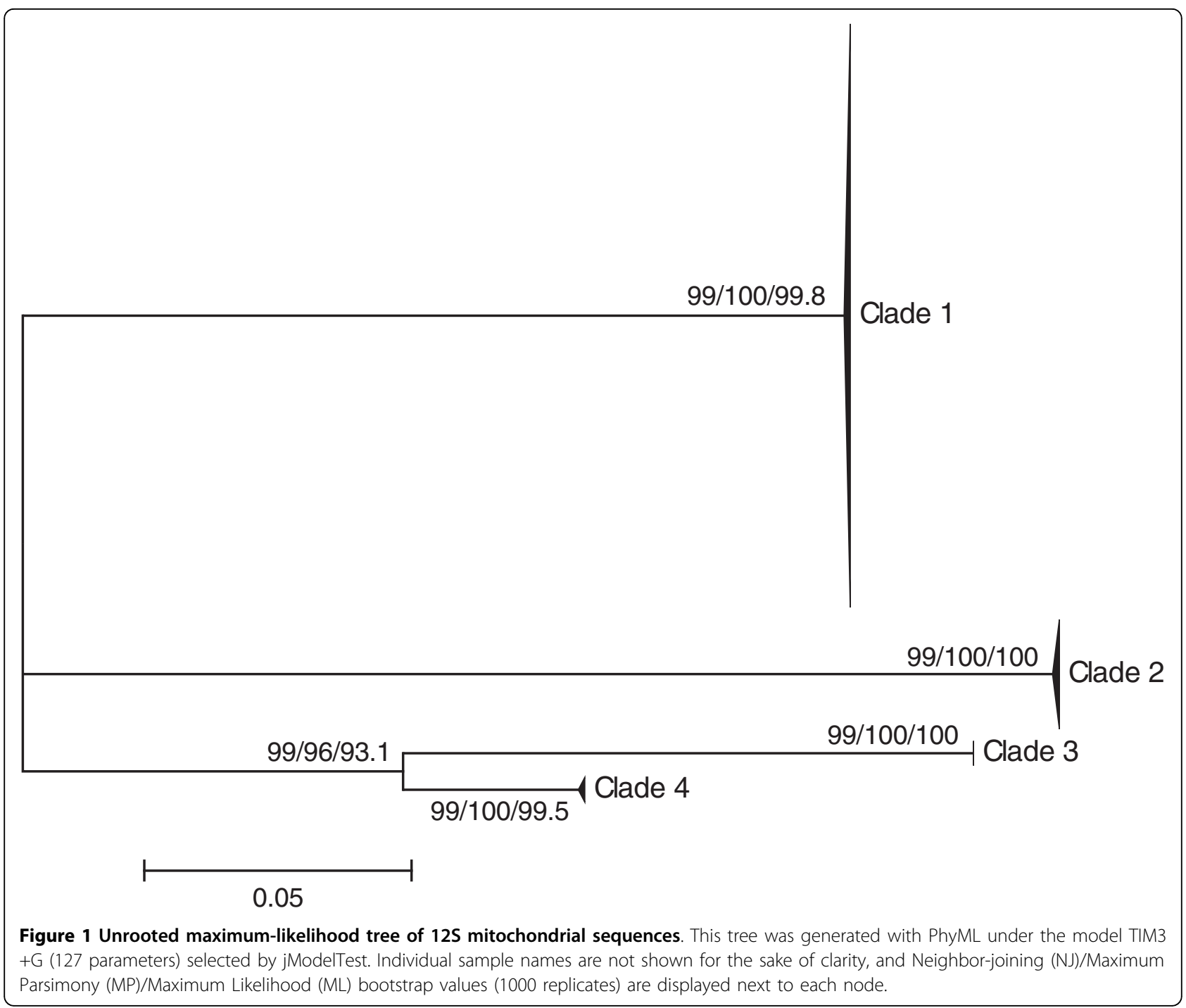

10 seconds. In Pozzo dei Cristalli, a 10-meter long stream with a stagnant pool in the middle, some Niphargus were observed to crawl on bacterial mats whereas others were swimming in the stagnant pool. As our 2007 and 2008 data showed that both Clades 1 and 2 were present in this location, 4 individuals of each behavioral type were collected in 2009 and analyzed morphologically and molecularly: all crawling Niphargus were found to belong to Clade 1, whereas all swimming individuals belonged to Clade 2 .

Even though Clade 3 was only present in Il Bugianardo where it co-occurred with Clade 2, it could be easily distinguished in the field due to its much larger size, allowing comparative behavioral observations of Clade 2 and Clade 3 individuals in this location. Clade 2 individuals were found to spend most of their time swimming in the deeper parts of the pool, whereas Clade 3 predominantly crawled on limestone boulders.

\section{Discussion}

Four Niphargus clades are present in Frasassi, among which only two are closely related to each other

Prior to this study, only one Niphargus species had been reported from the Frasassi cave system and this species, described as $N$. ictus, was supposed to be endemic to this locality $[14,29]$. Here we show that 4 molecularly distinct clades are actually present in Frasassi, with patristic distances (Table 2) between them higher than the 0.16 threshold proposed for species delimitation in Crustacea [34]. The perfect agreement between independent nuclear and mitochondrial datasets further suggests that these four clades are not just an instance of intraspecific variation but represent four distinct monophyletic taxa of putative species level. Among them, Clades 1-3 can be also be diagnosed morphologically and behaviorally (unfortunately, no intact representative of Clade 4 is presently available for morphological analyses, and 


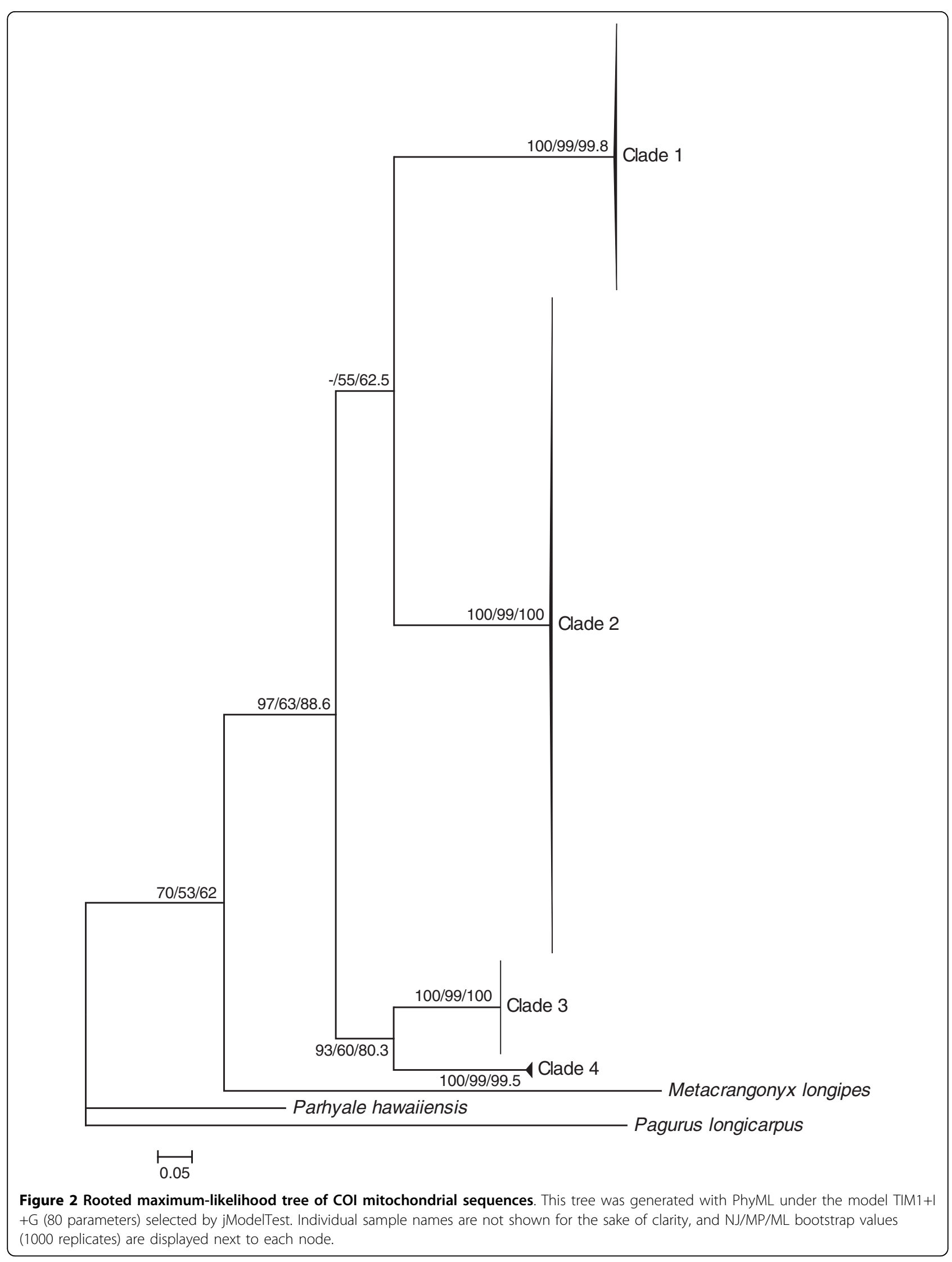




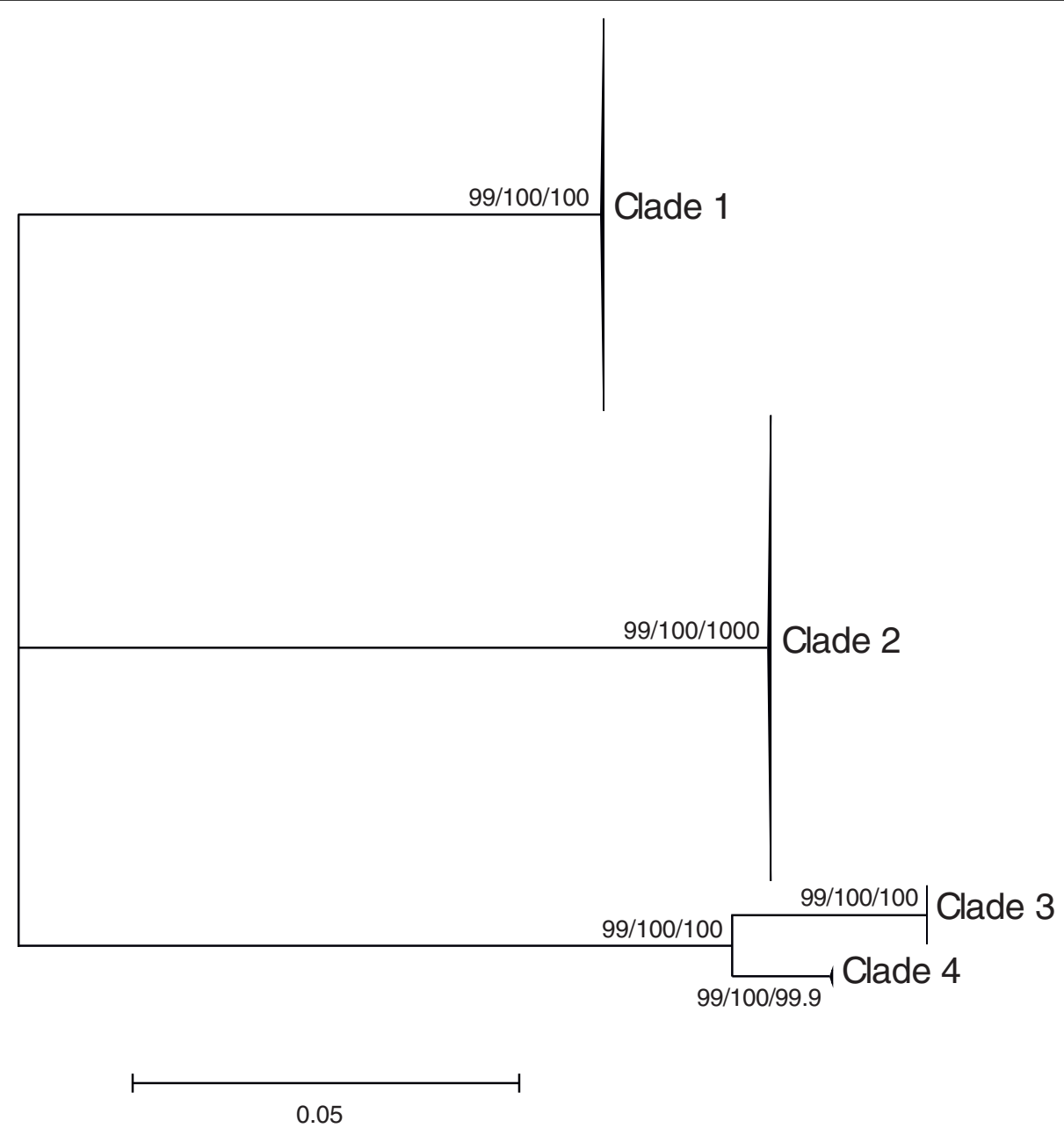

Figure 3 Unrooted maximum-likelihood tree of ITS nuclear sequences. This tree was generated with PhyML under the model TVM+G (40 parameters) selected by jModelTest. Individual sample names are not shown for the sake of clarity, and NJ/MP/ML bootstrap values (1000 replicates) are displayed next to each node.

the behavior of living individuals from this rare clade could not be observed). Moreover, there was no heterozygous individual harboring nuclear ITS sequences from more than one clade: thus, these four clades appear reproductively isolated from each other [37], which further suggests that they represent distinct species following the biological species criterion [38].

The most parsimonious explanation for the observed polyphyly of Niphargus within Frasassi (Figure 5) is that this cave system was colonized at least three times by different amphipod lineages since the start of its formation less than 1 million years ago [31]: one lineage that had only been reported until now from the Dinaric Region (Slovenia, Croatia, Herzegovina), a second lineage found presently on both sides of the Adriatic Sea (Italy, Croatia, Greece), and a third lineage (comprising Clades 3 and 4 from the present study) only found in Frasassi to date. Analysis of samples from caves in the surrounding area will be required to find out whether the closely related Clades 3 and 4 invaded the Frasassi cave system independently or if speciation occurred within Frasassi from their invading common ancestor.

Water chemistry and flow regime seem to influence the repartition of the four clades in Frasassi

The areas of occurrence of the four clades in Frasassi are overlapping (Figure 4) but show some correlation with groundwater chemistry and hydrological flow regimes. Clade 1 occurs only in shallow, flowing streams and predominantly at relatively low sulfide concentrations (45 to $150 \mu \mathrm{M}$ sulfide); however, sulfide tolerance does not appear to be a limiting factor for this clade since it is also found in Pozzo dei Cristalli, a stream characterized by much higher sulfide levels (up to 415 $\mu \mathrm{M}$ ). Clade 2 (that corresponds to the published description of $N$. ictus) is predominantly found in lakes 


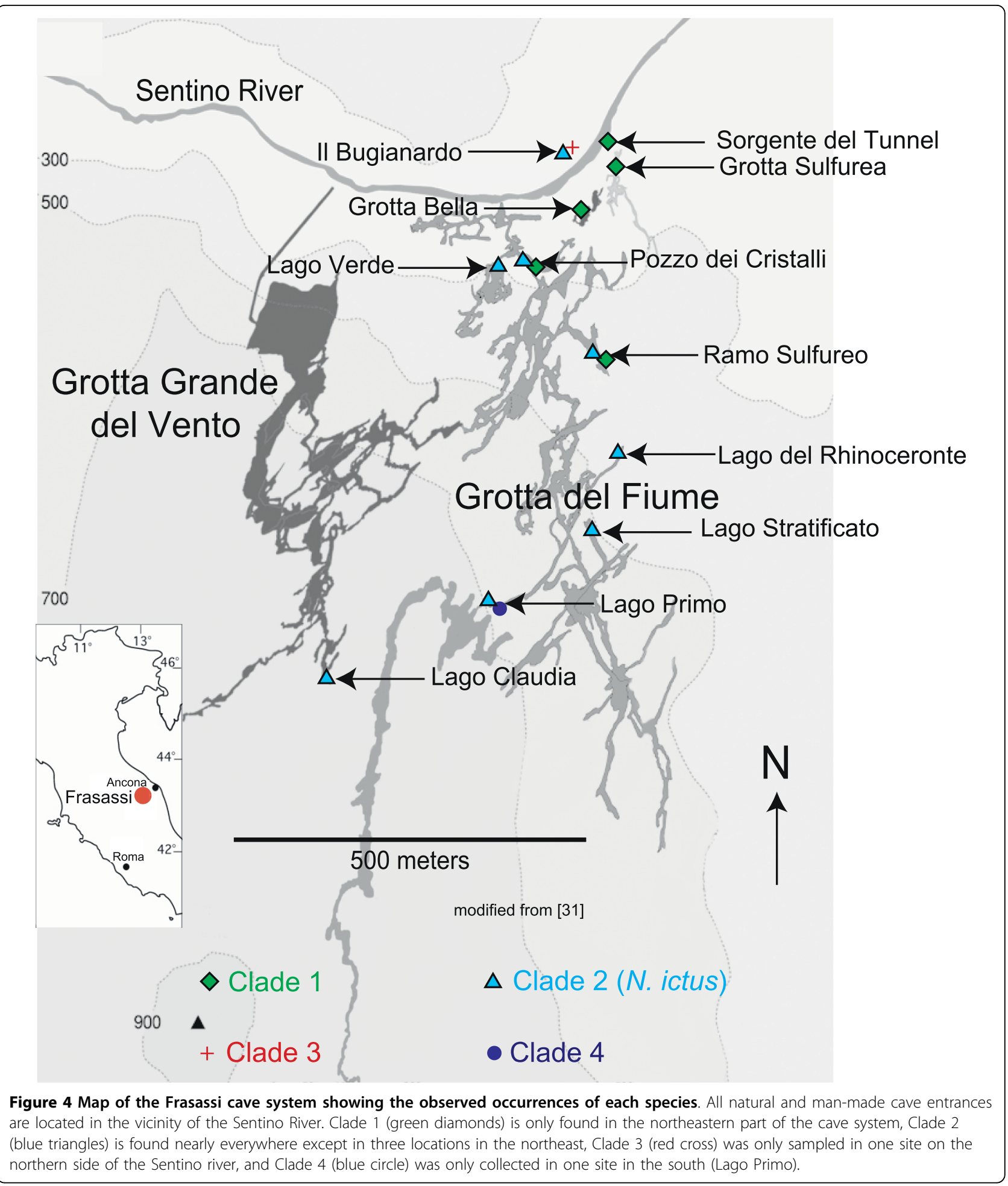

with calm and deep waters ( $>20 \mathrm{~cm}$ depth), with sulfide concentrations spanning the whole range of values measured in Frasassi (i.e., from non-detectable to $415 \mu \mathrm{M}$ sulfide). Clade 3 occurs only in Il Bugianardo, a location with no detectable sulfide that is also the only sampling site located north of the Sentino River. Clade 4 has so far only been collected from Lago Primo, a stratified lake with oxygenated water on top and reducing, sulfidic waters at depths greater than 3.5 meters (JL Macalady, pers. comm.). At a more local scale, members of various 
Table 1 Overview of the specimens analyzed (including a description of the sampling sites and their main geochemical parameters)

\begin{tabular}{|c|c|c|c|c|c|c|}
\hline \multirow[t]{2}{*}{ Sampling site (abbreviations) } & \multirow[t]{2}{*}{ Type of water body } & \multicolumn{2}{|c|}{ Geochemistry $^{a}$} & \multicolumn{3}{|c|}{$\begin{array}{c}\text { Number of specimens } \\
\text { analyzed (per collection } \\
\text { year) }\end{array}$} \\
\hline & & {$\left[\mathrm{H}_{2} \mathrm{~S}\right](\mu \mathrm{M})$} & {$\left[\mathrm{O}_{2}\right](\mu \mathrm{M})$} & 2007 & 2008 & 2009 \\
\hline II Bugianardo (BUG, BG) & Stagnant pool & n.d. & 151 & & 17 & \\
\hline Sorgente del Tunnel (ST) & Flowing stream & 136 & 31 & & & 8 \\
\hline Grotta Sulfurea (GS) & Stream with stagnant eddies & 118 & 51 & & 14 & 2 \\
\hline Grotta Bella (GB) & Flowing stream & 45 & 6 & & 8 & 1 \\
\hline Pozzo dei Cristalli (PDC, PC) & Flowing stream with stagnant pond caused by obstruction & 415 & 12 & 11 & 23 & 8 \\
\hline Lago Verde (LVE, LV) & Stagnant lake & 415 & 2 & 10 & 23 & \\
\hline Ramo Sulfureo (RS) & Stream with stagnant eddies & 109 & 10 & 7 & 18 & \\
\hline Lago del Rinoceronte (LRI) & Stagnant lake (stratified ${ }^{\mathrm{b}}$ ) & n.a & n.a. & & 8 & \\
\hline Lago Stratificato (LST) & Stagnant lake & n.a. & n.a. & & 5 & \\
\hline Lago Primo (LPR) & Stagnant lake (stratified ${ }^{\mathrm{b}}$ ) & n.a. & n.a. & & 6 & \\
\hline Lago Claudia (LCL, LC) & Stagnant lake & 45 & 8 & & 8 & 7 \\
\hline
\end{tabular}

clades were found to occupy different microhabitats in locations where they co-occur. In Pozzo dei Cristalli, where Clades 1 and 2 cohabitate, Clade 1 was restricted to fast-flowing portions of the stream that were less than $5 \mathrm{~cm}$ deep and Clade 2 to stagnant parts that were deeper than $20 \mathrm{~cm}$. In Il Bugianardo, Clades 2 and 3 cooccur in a small pool that is $10-50 \mathrm{~cm}$ deep: there, Clade 3 members were found crawling on limestone boulders and within interstitial crevices, whereas Clade 2 members were swimming in the deeper parts of the lake.

The "crawling" species (Clades 1 and 3) have restricted areas of repartition in comparison with the "swimming" Clade 2 (N. ictus) that was sampled everywhere except in three streams (Figure 4). Large lakes with deep water dominate the southern recesses of the Frasassi cave network, and a gradual slope causes water to flow towards the Sentino River. The remarkable swimming ability of $N$. ictus could enable it to move upstream and across large bodies of deep water, allowing it to occupy most of the water bodies within Frasassi (the question of whether $N$. ictus populations on both sides of the river

Table 2 Average patristic distances within and between clades (computed from the $\mathrm{COI}$ maximum likelihood tree)

\begin{tabular}{lllll}
\hline & Clade $\mathbf{1}$ & Clade 2 & Clade 3 & Clade 4 \\
\hline Clade 1 & 0.0045 & & & \\
\hline Clade 2 & 0.5638 & 0.0032 & & \\
\hline Clade 3 & 0.6561 & 0.5619 & 0.0004 & \\
\hline Clade 4 & 0.7021 & 0.6079 & 0.3596 & 0.0172 \\
\hline
\end{tabular}

are connected will require future work using highly variable markers such as microsatellites). Clade 1, on the other hand, might be restricted by its poor swimming ability to shallow streams (found only in northern parts of the cave system close to the Sentino River), whereas the limited distribution of Clade 3 may be either due to its inability to cross the barrier created by the Sentino River or to its lower tolerance to sulfide compared with Clades 1 and 2. Unlike Clade 2 ( N. ictus) that is found in most parts of the cave system (including deep recesses rarely visited by cavers), Clades 1 and 3 appear restricted to few, easy-to-reach locations and may require specific conservation efforts in the future.

\section{At least two of the Frasassi Niphargus clades are symbiotic}

When the symbiosis between Niphargus and sulfur-oxidizing bacteria was discovered in Frasassi [31], all the Niphargus individuals used in that study were assumed to be conspecific since $N$. ictus was the only species reported within the cave system [14,29]. The unexpected finding of four distinct clades in the present study prompted us to reexamine the previously published data regarding this symbiosis. Among these data, Niphargus individuals from the study sites Grotta Sulfurea, where only Clade 1 has been found, and Lago Verde, inhabited only by Clade 2 ( $N$. ictus), were both found to be symbiotic with sulfur-oxidizing Thiothrix bacteria using fluorescence in situ hybridization (FISH) analyses [31]. We have subsequently confirmed this finding by scanning electron microscopy and by sequencing bacterial 


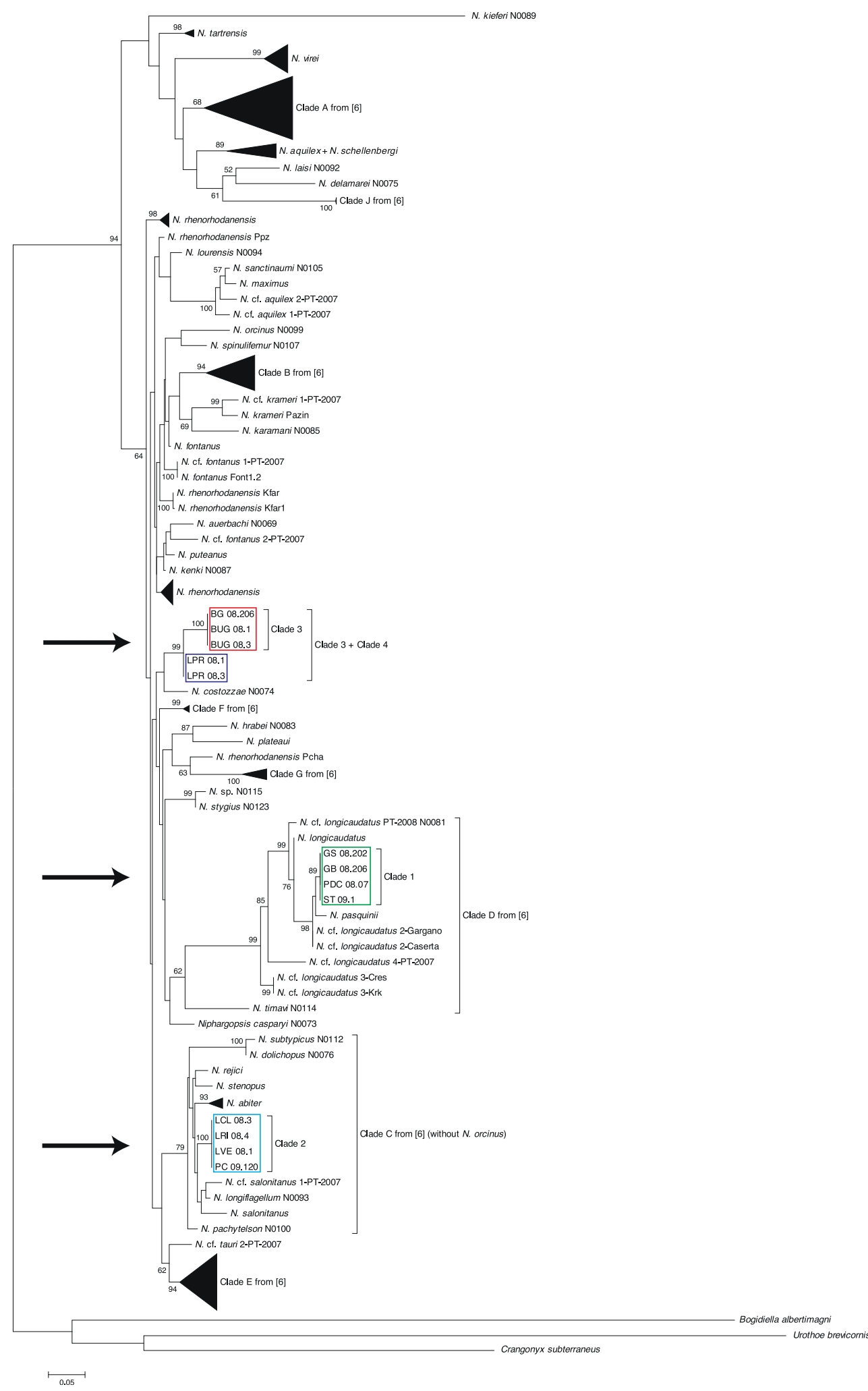

Figure 5 Maximum-likelihood $28 \mathrm{~S}$ phylogeny of the genus Niphargus. This tree was generated with PhyML under the model SYM+G (290 parameters) selected by jModelTest. For the sake of clarity, only ML bootstrap values higher than $50 \%$ are displayed and the long branches leading to Bogidiella albertimagni, Crangonyx subterraneous, Urathoe brevicornis and Niphargus kieferi are drawn with only half of their actual lengths. Clades 1-4 (arrows) are from the present study, Clades A-J are from [6]. 


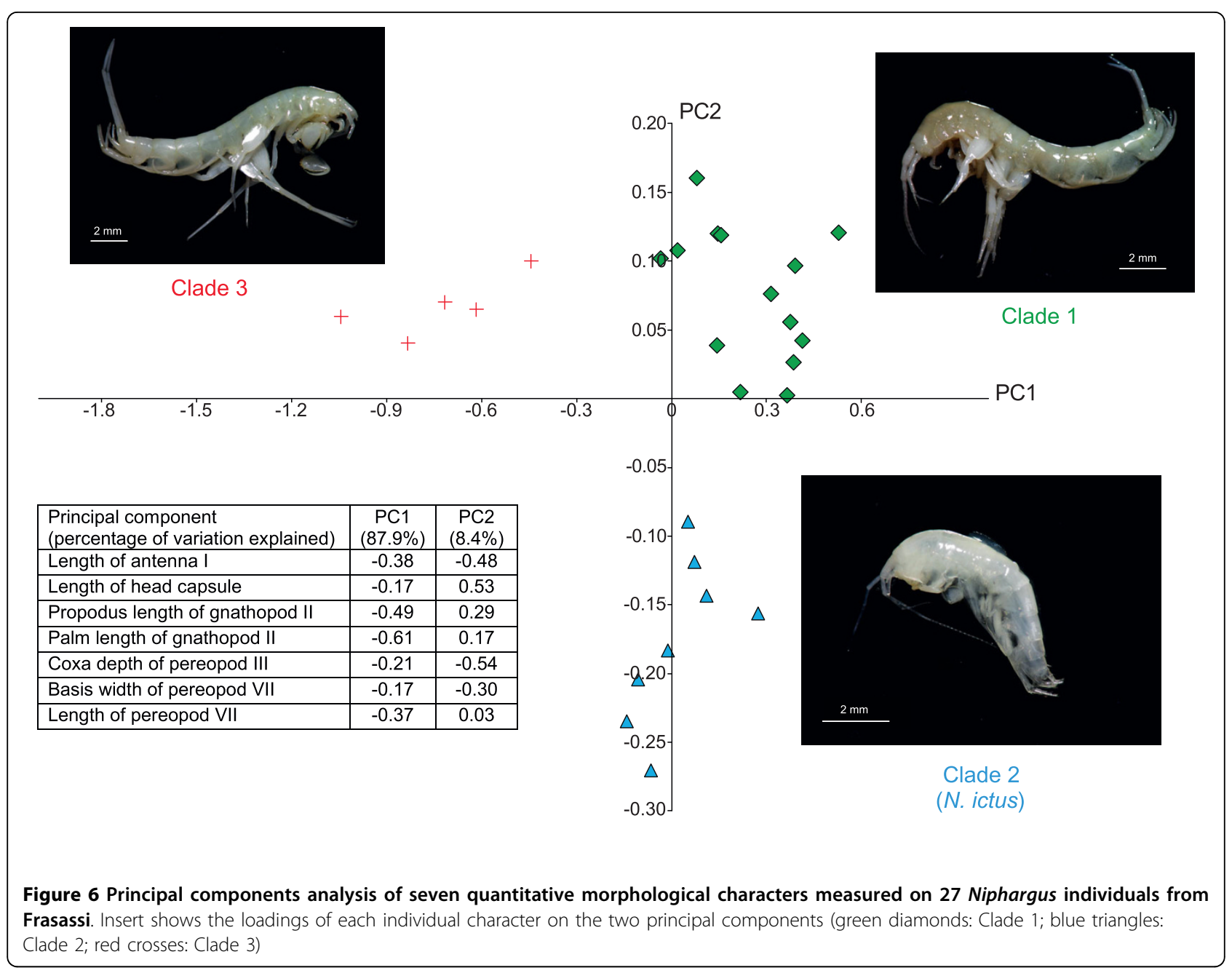

16S rDNA libraries (unpublished results). Additional investigations will be required to find out whether Clades 3 and 4 are also symbiotic, and whether bacterial symbionts are different between Niphargus clades.

\section{COI and ITS are useful molecular markers for the taxonomy of Niphargus}

Prior to the present study, the COI barcode marker [39] had only been sequenced for very few species of Niphargus $[7,8]$ whereas the ITS region of this genus had never been analyzed. Here we demonstrate that COI and ITS can conjointly be used to delineate Niphargus species, and may become of standard use in future taxonomic studies of Niphargus as they are already the most commonly used markers in other groups of organisms [40]. The 12S marker, on the other hand, is shorter and more difficult to align than COI, but can still prove useful when dealing with populations or individuals for which obtaining non-ambiguous COI sequences is difficult (which was the case here with our Clade 1, see Materials and Methods). As for nuclear markers, an aim in future studies should be to develop primers targeting variable regions other than ITS, such as introns, as it is only by constructing and comparing several independent gene trees that one may hope to build a species tree with a reasonable degree of confidence [41-43].

\section{Conclusions}

The molecular, morphological and behavioral data gathered in this study indicate that, instead of a single Niphargus species, the chemoautotrophic cave ecosystem of Frasassi hosts four distinct amphipod clades among which only two are closely related to each other; hence, there appears to have been at least three independent invasions of the Frasassi cave system. Moreover, the finding that two distantly related Niphargus clades harbor symbiotic Thiothrix bacteria paves the way for further studies concerning the origin and evolution of this unusual freshwater chemoautotrophic symbiosis. 


\section{Methods}

\section{Sample collection and processing}

A total of 184 Niphargus individuals were collected in the Grotta Grande del Vento - Grotta del Fiume (Frasassi) cave system in 2007, 2008 and 2009 (Table 1) using tweezers or nets and preserved in $70 \%$ ethanol or RNAlater $^{\circledR}$ (Ambion). Most individuals were stored in single tubes, except for some population samplings where several individuals were collected together in a single large vial; even in such cases, we never encountered any evidence of DNA cross-contamination between our samples. Early DNA extractions were performed using one half of each individual; subsequently, only two appendages (one gnathopod and one pereiopod) from each individual were used for DNA extraction. All DNA extractions were performed using DNeasy ${ }^{\circledR}$ Blood \& Tissue kits (Qiagen) following the manufacturer's instructions.

\section{PCR amplification and sequencing}

Partial COI (mitochondrial), 12S (mitochondrial) and 28S (nuclear) sequences were obtained using published primers (Table 3$)$. PCR reactions $(25 \mu \mathrm{L})$ were obtained by mixing $16 \mu \mathrm{L} \mathrm{H} \mathrm{H}_{2} 0,2.5 \mu \mathrm{L}$ PCR buffer, $1.3 \mu \mathrm{L}$ DMSO, $1 \mu \mathrm{L} \mathrm{MgCl} 2$ (50 mM), $0.5 \mu \mathrm{L}$ dNTP Mix (40 mM total), $0.3 \mu \mathrm{L}$ each primer $(25 \mathrm{mM}), 3 \mu \mathrm{L}$ DNA extract and $0.15 \mu \mathrm{L} \mathrm{BIOTAQ}^{\circledR}$ (Bioline) in $200 \mu \mathrm{L}$ Eppendorf tubes; PCR conditions consisted of $3 \mathrm{~min}$ at $94^{\circ} \mathrm{C}$, then 50 cycles of $30 \mathrm{sec}$ at $94^{\circ} \mathrm{C}, 1 \mathrm{~min}$ at $45^{\circ} \mathrm{C}$ and $1 \mathrm{~min}$ at $72^{\circ} \mathrm{C}$. Two new primers (Table 3 ) were designed with the help of Primer3 [44] based on published amphipod $18 \mathrm{~S}[45,46]$ and $28 \mathrm{~S}$ [6-8] sequences, and used to amplify the complete ITS region (together with flanking portions of the $18 \mathrm{~S}$ and $28 \mathrm{~S}$ genes) by mixing $16.8 \mu \mathrm{L}$
$\mathrm{H}_{2} 0,2.5 \mu \mathrm{L}$ Red Taq buffer, $1.3 \mu \mathrm{L}$ DMSO, $0.5 \mu \mathrm{L}$ dNTP Mix (40 mM total), $0.3 \mu \mathrm{L}$ each primer $(25 \mathrm{mM})$, $3 \mu \mathrm{L}$ DNA extract and $0.6 \mu \mathrm{L}$ Red Taq (Sigma) in $200 \mu \mathrm{L}$ Eppendorf tubes; PCR conditions for this marker consisted of $1 \mathrm{~min}$ at $94^{\circ} \mathrm{C}$, then 50 cycles of $30 \mathrm{sec}$ at $94^{\circ} \mathrm{C}, 30 \mathrm{sec}$ at $53^{\circ} \mathrm{C}$ and $3 \mathrm{~min}$ at $72^{\circ} \mathrm{C}$.

PCR products were cleaned using the QIAquick ${ }^{\circledR}$ PCR Purification kit (Qiagen) and sequencing was performed using the same primers as for amplification. End-based sequencing turned out to be sufficient for the COI and $12 \mathrm{~S}$ markers due to their relatively short lengths (658 bp and 477-480 bp, respectively). The $28 \mathrm{~S}$ and ITS markers, however, were much longer (981-993 bp and 1589-2100 $\mathrm{bp}$, respectively) and additional sequencing was performed using internal primers (Table 3 ).

\section{Molecular data analyses}

Chromatograms were inspected, assembled and cleaned using Sequencher 4 (Gene Codes). ITS sequencing yielded a single, homozygous sequence for 164 individuals out of 184: as for the others, the chromatograms of 17 individuals comprised one double peak (i.e., these individuals possessed two nearly identical sequence types differing by one base), one individual had two double peaks, and two others had numerous double peaks (as expected when simultaneously sequencing two sequence types of different lengths [47]). Obtaining sequences was trivial in the first case, whereas the second case was solved using Clark's method [48] and the third case was phased using CHAMPURU [49]. For individuals comprising two distinct ITS types, sequence types were given the name of the individual followed by "a" or "b" and were all included in subsequent analyses. In order to allow comparison with Niphargus sequences

Table 3 List of the primers used in this study

\begin{tabular}{|c|c|c|c|c|}
\hline Marker & Direction & Purpose & Sequence & Reference \\
\hline $\mathrm{COI}$ & Forward & $P C R+$ sequencing & 5'-GGTCAACAAATCATAAAGATATTGG-3' & {$[66]$} \\
\hline $\mathrm{COI}$ & Reverse & $P C R+$ sequencing & 5'-TAAACTTCAGGGTGACCAAAAAATCA-3' & {$[66]$} \\
\hline $12 S$ & Forward & $P C R+$ sequencing & 5'-GCCAGCAGCCGCGGTTA-3' & {$[67]$} \\
\hline $12 S$ & Reverse & $P C R+$ sequencing & 5'-CCTACTITGTTACGACTTAT-3' & {$[67]$} \\
\hline 285 & Forward & $P C R+$ sequencing & 5'-CAAGTACCGTGAGGGAAAGTT-3' & {$[68]$} \\
\hline $28 \mathrm{~S}$ & Reverse & $P C R+$ sequencing & 5'-AGGGAAACTTCGGAGGGAACC-3' & {$[68]$} \\
\hline $28 \mathrm{~S}$ & Forward & sequencing & 5'-AAACACGGGCCAAGGAGTAT-3' & this article \\
\hline $28 \mathrm{~S}$ & Reverse & sequencing & 5'-TATACTCCTTGGCCCGTGTT-3' & this article \\
\hline ITS & Forward & $P C R+$ sequencing & 5'-TCCGAACTGGTGCACTTAGA-3' & this article \\
\hline ITS & Reverse & $P C R+$ sequencing & 5'-TCCAAGCTCCATTGGCTTAT-3' & this article \\
\hline$\overline{\mathrm{ITS}}$ & Forward & sequencing & 5'-CGCTGCCATTCTCACACTTA-3' & this article \\
\hline ITS & Reverse & sequencing & 5'-ACTCTGAGCGGTGGATCACT-3' & this article \\
\hline$\overline{\mathrm{ITS}}$ & Forward & sequencing & 5'-AAGGCTATAGCTGGCGATCA-3' & this article \\
\hline ITS & Reverse & sequencing & 5'-TCAGCGGGTAACCTCTCCTA-3' & this article \\
\hline
\end{tabular}


present in GenBank, an additional 28S fragment was sequenced from 13 individuals representative of the four clades obtained using ITS (only one $28 \mathrm{~S}$ haplotype was found in each sample analyzed).

We attempted to sequence the COI reference barcode fragment of all 184 individuals; however, the COI sequences obtained from 5 samples turned out to be of bacterial origin, whereas the chromatograms of 36 other individuals contained double or triple peaks indicating a mixture of several sequences and could not be interpreted unambiguously. Therefore, the COI sequences of only 143 Niphargus specimens out of 184 were used in further analyses. In order to ascertain the mitochondrial background of the remaining individuals, we resorted to sequencing $12 \mathrm{~S}$ as a second marker: none of the samples for which COI sequencing had yielded double or triple peaks had more than one $12 \mathrm{~S}$ sequence, whereas one individual that had a single COI sequence was found to possess two divergent $12 \mathrm{~S}$ haplotypes (the sequences from this individual were discarded from subsequent analyses). Our final $12 \mathrm{~S}$ dataset comprised 61 sequences.

All individuals that had double or triple peaks in their COI chromatograms belonged to Clade 1 . The most likely explanation for the presence of multiple peaks is that one or several nuclear-transferred COI pseudogenes $[50,51]$ were sequenced together with the mitochondrial COI; heteroplasmy, i.e. the occurrence of several distinct mitochondrial lineages within one individual, is a less probable explanation since there was no multiple peaks in the $12 \mathrm{~S}$ chromatograms obtained from these individuals. In the same way, the presence of two very divergent $12 \mathrm{~S}$ sequences in one individual from Clade 2 that had a single COI sequence strongly suggests that one of the two $12 \mathrm{~S}$ sequences is a nuclear pseudogene.

All sequences obtained were deposited in public databases [GenBank: GU973003-GU973423]. COI sequences of the hermit crab Pagurus longicarpus and of the gammarid amphipods Parhyale hawaiiensis and Metacrangonyx longipes were extracted from their published complete mitochondrial genomes [52-54] and used to root the COI tree, whereas sequences from the amphipods Bogidiella albertimagni, Crangonyx subterraneus and Urothoe brevicornis were obtained from GenBank in order to root the $28 \mathrm{~S}$ phylogeny. The ITS and $12 \mathrm{~S}$ trees were left unrooted as Niphargus sequences for these markers were markedly divergent from their closest available relatives.

Sequences were aligned manually in MEGA4 [55] for COI and using MAAFT's Q-INS-I option [56,57] for ITS, $12 \mathrm{~S}$ and $28 \mathrm{~S}$. The best-suited nucleotide model for each alignment was determined among 88 possible models following the Akaike Information Criterion [58] and the Bayesian Information Criterion [59] (whenever the two criteria disagreed, the more parameter-rich model was selected) as implemented in jModelTest [60], and used to build Maximum Likelihood (ML) phylogenetic trees with PhyML 3.0 [61]. In order to investigate the sensitivity of the results to variations in methods of phylogenetic reconstruction, Neighbor-Joining (NJ; nucleotide model: Kimura 2-parameter, uniform rates among sites, pairwise deletion) and Maximum Parsimony (MP; search options: $\mathrm{CNI}$ level $=1$, initial tree by random addition with 10 replications, use all sites) analyses were also conducted on the same alignments using MEGA4. Furthermore, the robustness of the nodes obtained using each method was estimated by performing 1,000 bootstrap replicates [62]. Patristic distances were computed from the COI ML tree using the program PATRISTIC [63].

\section{Morphological analyses}

A set of 27 ethanol-preserved samples from Il Bugianardo, Grotta Sulfurea, Pozzo dei Cristalli, Lago Verde, Ramo Sulfureo (5 individuals from each location) and Lago Primo ( 2 individuals), including both females and males but no juveniles, was examined for seven quantitative morphological characters that had previously proved useful for taxonomic investigation of Niphargus amphipods [64]: the length of the $1^{\text {st }}$ antenna, the length of the head capsule, the length of the propodus of the $2^{\text {nd }}$ gnathopod, the length of the palm of the $2^{\text {nd }}$ gnathopod, the depth of the coxal plate of the $3^{\text {rd }}$ pereopod, the width of the basal article of the $7^{\text {th }}$ pereopod and the length of the $7^{\text {th }}$ pereopod. Among the 27 samples, 14 turned out to belong to Clade 1,8 to Clade 2 and 5 to Clade 3 (unfortunately, none of the two specimens from Clade 4 collected to date was intact enough to be included in this morphological analysis). Niphargus specimens were partially dissected in glycerin and mounted on slides. Appendages were photographed with an Olympus camera ColorView III mounted on a stereomicroscope Olympus DP Soft and measured using the program ANALYSIS (Olympus Soft Imaging Solutions). Principal components analysis was performed on the covariance matrix of the log-transformed measurements using the program PAST [65].

\section{Behavioral observations}

Observations were conducted in May-June 2009 on about 200 individuals in five locations within the cave system: Il Bugianardo (Clades 2 and 3), Sorgente del Tunnel (Clade 1), Grotta Sulfurea (Clade 1), Pozzo dei Cristalli (Clades 1 and 2) and Lago Verde (Clade 2). Unfortunately the behavior of Clade 4 individuals could not be observed as they are found in a location (Lago Primo) that only very experienced cavers can access. We noted down the behavior of many individuals among the ones that we could see (since no attempt was made to mark them, some individuals were probably observed several times). When Niphargus amphipods did not 
swim spontaneously, we disturbed them by probing them with a pipette in order to document their swimming abilities. Digital photographs and videos were also taken whenever possible.

\begin{abstract}
Acknowledgements
Thanks to Cene Fišer for performing the morphometric analysis presented in Figure 6 and for useful discussions. Thanks also to Jan Bauermeister, Simone Cerioni, Sandro Galdenzi, Dan Jones, Jennifer Macalady, and Sandro Mariani for helping with sample collection, to Alessandro Montanari for logistical support at the Osservatorio Geologico di Coldigioco, and to Tobias Kahland and Melanie Heinemann for assistance with labwork. The helpful comments of Markus Pfenninger and two anonymous reviewers on a previous version of the manuscript are gratefully acknowledged. This study was funded by the German Initiative of Excellence and fieldwork was supported by the National Geographic Committee for Research \& Exploration (Grant \# 8387-08 to SD). GW acknowledges funding from the German Science Foundation (DFG). This is contribution number 46 from the Courant Research Centre "Geobiology".
\end{abstract}

\section{Note added in proofs}

While this article was being reviewed, Karaman et al. published formal descriptions of Clade 1 and Clade 3 as Niphargus frasassianus and Niphargus montanarius, respectively (Zootaxa 2010, 2439:35-52).

\section{Author details}

${ }^{1}$ Courant Research Centre "Geobiology", University of Göttingen, 37077 Göttingen, Germany. ${ }^{2}$ Department für Geo- und Umweltwissenschaften \& GeoBio-Center ${ }^{\text {LMU }}$, Ludwig-Maximilians-Universität München, 80333 München, Germany.

\section{Authors' contributions}

JFF participated in fieldwork, designed primers, performed molecular labwork and computational analyses, conducted behavioral observations and drafted the manuscript. GW participated in initiating the study and revised the manuscript. SD designed and supervised the study, collected samples and geochemical data, conducted behavioral observations and revised the manuscript. All authors read and approved the final manuscript.

Received: 15 February 2010 Accepted: 9 June 2010

Published: 9 June 2010

\section{References}

1. Danielopol DL, Griebler C, Gunatilaka A, Notenboom J: Present state and future prospects for groundwater ecosystems. Environmental Conservation 2003, 30:104-130.

2. Botoseanu L: Stygofauna mundi: a faunistic, distributional, and ecological synthesis of the world fauna inhabiting subterranean waters (including the marine interstitial). Leiden: Brill 1986.

3. Väinölä R, Witt J, Grabowski M, Bradbury J, Jazdzewski K, Sket B: Global diversity of amphipods (Amphipoda; Crustacea) in freshwater. Hydrobiologia 2008, 595:241-255.

4. Ginet R: Ecologie, éthologie et biologie de Niphargus (Amphipodes Gammaridés hypogés). Annales de Spéléologie 1960, 15:129-376.

5. Gibert J: Recherches sur la pigmentation de Niphargus virei Chevreux, 1896. Crustaceana. Supplement 1977, 4:45-57.

6. Fišer C, Sket B, Trontelj P: A phylogenetic perspective on 160 years of troubled taxonomy of Niphargus (Crustacea: Amphipoda). Zoologica Scripta 2008, 37:665-680

7. Lefébure T, Douady CJ, Gouy M, Trontelj P, Briolay J, Gibert J: Phylogeography of a subterranean amphipod reveals cryptic diversity and dynamic evolution in extreme environments. Molecular Ecology 2006, 15:1797-1806.

8. Lefébure T, Douady CJ, Malard F, Gibert J: Testing dispersal and cryptic diversity in a widely distributed groundwater amphipod (Niphargus rhenorhodanensis). Molecular Phylogenetics and Evolution 2007, 42:676-686.

9. Trontelj P, Douady CJ, Fišer C, Gibert J, Gorički Š, Lefébure T, Sket B, Zakšek V: A molecular test for cryptic diversity in ground water: how large are the ranges of macro-stygobionts? Freshwater Biology 2009, 54:727-744

10. Witt JD, Threloff DL, Hebert PDN: DNA barcoding reveals extraordinary cryptic diversity in an amphipod genus: implications for desert spring conservation. Molecular Ecology 2006, 15:3073-3082.

11. Gervasio V, Berg DJ, Lang BK, Allan NL, Guttman SI: Genetic diversity in the Gammarus pecos species complex: Implications for conservation and regional biogeography in the Chihuahuan Desert. Limnology and Oceanography 2004, 49:520-531.

12. Gibert J, Deharveng L: Subterranean ecosystems: a truncated functional biodiversity. BioScience 2002, 52.

13. Sarbu SM, Kane TC, Kinkle BK: A chemoautotrophically based cave ecosystem. Science 1996, 272:1953-1955.

14. Sarbu SM, Galdenzi S, Menichetti M, Gentile G: Geology and biology of the Frasassi caves in central Italy: an ecological multidisciplinary study of a hypogenic cave system. In Ecosystems of the World 30. Subterranean ecosystems. Edited by: Wilkens H, Culver DC, Humphreys WF. Amsterdam: Elsevier; 2000:359-378.

15. Por FD: Ophel: a groundwater biome based on chemoautotrophic resources. The global significance of the Ayyalon cave finds, Israel. Hydrobiologia 2007, 592:1-10.

16. Grieshaber MK, Völkel S: Animal adaptations for tolerance and exploitation of poisonous sulfide. Annual Review of Physiology 1998, 60:33-53.

17. Somero GN, Childress JJ, Anderson AE: Transport, metabolism, and detoxification of hydrogen sulfide in animals from sulfide-rich marine environments. CRC Critical Reviews in Aquatic Sciences 1989, 1:591-614.

18. Nicholls $P$ : The effect of sulphide on cytochrome $\mathrm{aa}_{3}$ isosteric and allosteric shifts of the reduced $\alpha$-peak. Biochimica et Biophysica Acta 1975, 396:24-35.

19. Cline JD, Richards FA: Oxygenation of hydrogen sulfide in seawater at constant salinity, temperature, and pH. Environmental Science \& Technology 1969, 3:838-843.

20. Fenchel TM, Riedl RJ: The sulfide system: a new biotic community underneath the oxidized layer of marine sand bottoms. Marine Biology 1970, 7:255-268.

21. Johnson KS, Beehler CL, Sakamoto-Arnold CM, Childress JJ: In situ measurements of chemical distributions in a deep-sea hydrothermal vent field. Science 1986, 231:1139-1141.

22. Sket B: The ecology of anchihaline caves. TREE 1996, 11:221-225.

23. Engel AS: Observations on the biodiversity of sulfidic karst habitats. Journal of Cave and Karst Studies 2007, 69:187-206.

24. Bagarinao T: Sulfide as an environmental factor and toxicant: tolerance and adaptations in aquatic organisms. Aquatic Toxicology 1992, 24:21-62.

25. Sandberg-Kilpi E, Vismann B, Hagerman L: Tolerance of the Baltic amphipod Monoporeia affinis to hypoxia, anoxia and hydrogen sulfide. Ophelia 1999, 50:61-68.

26. Theede H, Ponat A, Hiroki K, Schlieper C: Studies on the resistance of marine bottom invertebrates to oxygen-deficiency and hydrogen sulphide. Marine Biology 1969, 2:325-337.

27. Oseid DM, Smith LL Jr: Factors influencing acute toxicity estimates of hydrogen sulfide to freshwater invertebrates. Water Research 1974, 8:739-746.

28. Knezovich JP, Steichen DJ, Jelinski JA, Anderson SL: Sulfide tolerance of four marine species used to evaluate sediment and pore-water toxicity. Bulletin of Environmental Contamination and Toxicology 1996, 57:450-457.

29. Bertolani R, Manicardi GC, Rebecchi L: Faunistic study in the karst complex of Frasassi (Genga, Italy). International Journal of Speleology 1994, 23:61-77.

30. Karaman GS: New data on the genus Niphargus Schiödte (fam. Niphagidae) in Italy and adjacent regions. Bollettino del Museo Civico di Storia Naturale di Verona 1985, 12:209-228.

31. Dattagupta S, Schaperdoth I, Montanari A, Mariani S, Kita N, Valley JW, Macalady JL: A novel symbiosis between chemoautotrophic bacteria and a freshwater cave amphipod. The ISME Journal 2009, 3:935-943.

32. Dubilier N, Bergin C, Lott C: Symbiotic diversity in marine animals: the art of harnessing chemosynthesis. Nature Reviews Microbiology 2008, 6:725-740.

33. Macalady JL, Dattagupta S, Schaperdoth I, Jones DS, Druschel GK, Eastman D: Niche differentiation among sulfur-oxidizing bacterial populations in cave waters. The ISME Journal 2008, 2:590-601. 
34. Lefébure T, Douady CJ, Gouy M, Gibert J: Relationship between morphological taxonomy and molecular divergence within Crustacea: Proposal of a molecular threshold to help species delimitation. Molecular Phylogenetics and Evolution 2006, 40:435-447.

35. Dahl E: The Amphipod functional model and its bearing upon systematics and phylogeny. Zoologica Scripta 1977, 6:221-228.

36. Sket B, Karaman GS: Niphargus rejici (Amphipoda), its relatives in the Adriatic islands, and its possible relations to S.W. Asian taxa. Stygologia 1990, 5:153-172.

37. Doyle JJ: The irrelevance of allele tree topologies for species delimitation, and a non-topological alternative. Systematic Botany 1995, 20:574-588.

38. de Queiroz K: Species concepts and species delimitation. Systematic Biology 2007, 56:879-886.

39. Hebert PDN, Cywinska A, Ball SL, deWaard JR: Biological identifications through DNA barcodes. Proceedings of the Royal Society. Biological Sciences 2003, 270:313-321.

40. Hajibabaei $M$, Singer GAC, Hebert PDN, Hickey DA: DNA barcoding: how it complements taxonomy, molecular phylogenetics and population genetics. Trends in Genetics 2007, 23:167-172.

41. Doyle JJ: Gene trees and species trees: molecular systematics as onecharacter taxonomy. Systematic Botany 1992, 17:144-163.

42. Nichols R: Gene trees and species trees are not the same. TREE 2001, 16:358-364.

43. Pamilo $P$, Nei M: Relationships between gene trees and species trees. Molecular Biology and Evolution 1988, 5:568-583.

44. Rozen S, Skaletsky H: Primer3 on the WWW for general users and for biologist programmers. In Bioinformatics Methods and Protocols. Edited by: Misener S, Krawetz SA. Totowa, NJ: Humana Press; 2000:365-386.

45. Englisch U, Coleman CO, Wägele JW: First observations on the phylogeny of the families Gammaridae, Crangonyctidae, Melitidae, Niphargidae, Megaluropidae and Oedicerotidae (Amphipoda, Crustacea), using small subunit rDNA gene sequences. Journal of Natural History 2003, 37:2461-2486.

46. Englisch U, Koenemann S: Preliminary phylogenetic analysis of selected subterranean amphipod crustaceans, using small subunit rDNA gene sequences. Organisms Diversity \& Evolution 2001, 1:139-145.

47. Flot JF, Tillier A, Samadi S, Tillier S: Phase determination from direct sequencing of length-variable DNA regions. Molecular Ecology Notes 2006, 6:627-630.

48. Clark A: Inference of haplotypes from PCR-amplified samples of diploid populations. Molecular Biology and Evolution 1990, 7:111-122.

49. Flot JF: CHAMPURU 1.0: a computer software for unraveling mixtures of two DNA sequences of unequal lengths. Molecular Ecology Notes 2007 7:974-977.

50. Lopez JV, Cevario S, O'Brien SJ: Complete nucleotide sequences of the domestic cat (Felis catus) mitochondrial genome and a transposed mtDNA tandem repeat (Numt) in the nuclear genome. Genomics 1996, 33:229-246.

51. Richly E, Leister D: NUMTs in sequenced eukaryotic genomes. Molecular Biology and Evolution 2004, 21:1081-1084.

52. Bauzà-Ribot MM, Jaume D, Juan C, Pons J: The complete mitochondrial genome of the subterranean crustacean Metacrangonyx longipes (Amphipoda): A unique gene order and extremely short control region. Mitochondrial DNA 2009, 20:88-99.

53. Cook CE, Yue Q, Akam M: Mitochondrial genomes suggest that hexapods and crustaceans are mutually paraphyletic. Proceedings of the Royal Society B: Biological Sciences 2005, 272:1295-1304.

54. Hickerson MJ, Cunningham CW: Dramatic mitochondrial gene rearrangements in the hermit crab Pagurus longicarpus (Crustacea, Anomura). Molecular Biology and Evolution 2000, 17:639-644.

55. Tamura K, Dudley J, Nei M, Kumar S: MEGA4: Molecular Evolutionary Genetics Analysis (MEGA) software version 4.0. Molecular Biology and Evolution 2007, 24:1596-1599.

56. Katoh K, Misawa K, Kuma K, Miyata T: MAFFT: a novel method for rapid multiple sequence alignment based on fast Fourier transform. Nucl. Acids Res 2002, 30:3059-3066.

57. Katoh $\mathrm{K}$, Toh $\mathrm{H}$ : Improved accuracy of multiple ncRNA alignment by incorporating structural information into a MAFFT-based framework. BMC Bioinformatics 2008, 9:212.
58. Akaike $\mathrm{H}$ : A new look at the statistical model identification. IEEE Transactions on Automatic Control 1974, 19:716-723.

59. Schwartz G: Estimating the dimension of a model. The Annals of Statistic $1978,6: 461-464$.

60. Posada D: jModelTest: Phylogenetic model averaging. Molecular Biology and Evolution 2008, 25:1253-1256

61. Guindon S, Gascuel O: A simple, fast, and accurate algorithm to estimate large phylogenies by maximum likelihood. Systematic Biology 2003, 52:696-704.

62. Felsenstein J: Confidence limits on phylogenies: an approach using the bootstrap. Evolution 1985, 39:783-791.

63. Fourment M, Gibbs M: PATRISTIC: a program for calculating patristic distances and graphically comparing the components of genetic change. BMC Evolutionary Biology 2006, 6:1.

64. Fišer $C$, Trontelj $P$, Luštrik R, Sket B: Towards a unified taxonomy of Niphargus (Crustacea:Amphipoda): a review of morphological variability. Zootaxa 2009, 2061.

65. Hammer $\varnothing$, Harper DAT, Ryan PD: PAST: paleontological statistics software package for education and data analysis. Palaeontologia Electronica 2001, 4:4.

66. Folmer O, Black M, Hoeh W, Lutz R, Vrijenhoek R: DNA primers for amplification of mitochondrial cytochrome $c$ oxidase subunit I from diverse metazoan invertebrates. Molecular Marine Biology and Biotechnology 1994, 3:294-299.

67. Trontelj P, Utevsky SY: Celebrity with a neglected taxonomy: molecular systematics of the medicinal leech (genus Hirudo). Molecular Phylogenetics and Evolution 2005, 34:616-624.

68. Verovnik R, Sket B, Trontelj P: The colonization of Europe by the freshwater crustacean Asellus aquaticus (Crustacea: Isopoda) proceeded from ancient refugia and was directed by habitat connectivity. Molecular Ecology 2005, 14:4355-4369.

doi:10.1186/1471-2148-10-171

Cite this article as: Flot et al:: Unsuspected diversity of Niphargus amphipods in the chemoautotrophic cave ecosystem of Frasassi, central Italy. BMC Evolutionary Biology 2010 10:171.

\section{Submit your next manuscript to BioMed Central and take full advantage of:}

- Convenient online submission

- Thorough peer review

- No space constraints or color figure charges

- Immediate publication on acceptance

- Inclusion in PubMed, CAS, Scopus and Google Scholar

- Research which is freely available for redistribution

Submit your manuscript at www.biomedcentral.com/submit
Biomed Central 